\title{
Jogos Computadorizados para Aprendizagem Matemática no Ensino Fundamental: Refletindo a partir dos Interesses dos Educandos
}

\section{Cibele Ziani Figueiredo* João Ricardo Bittencourt**}

Resumo. O presente artigo apresenta o relato de uma pesquisa sobre a Educação Matemática e Jogos Computadorizados realizada com alunos de quinta série do Ensino Fundamental de duas escolas da rede pública e uma de ensino particular da cidade de Santa Maria - RS. Investigou-se a relação dos alunos com os gêneros de jogos computadorizados, com os conteúdos de matemática, da série, e as suas expectativas de um jogo diferenciado utilizando as novas tecnologias, objetivando deste modo destacar a relevância de mudanças metodológicas que atendam às necessidades recorrentes dos educandos. A pesquisa focalizou a importância da interdisciplinaridade no processo de ensino/aprendizagem de matemática, intensificando o uso de jogos computadorizados - forma na qual os educandos se identificam -, colaborando para uma aprendizagem significativa e contextualizada, relacionando o seu meio sociocultural às novas tecnologias. Palavras chaves: Aprendizagem matemática, jogos computadorizados e interdisciplinaridade.

\section{Computer Games for Math Learning in Basic Degree: A Reflection about Students Needs}

\begin{abstract}
The goal of this paper is show the results of survey has ocurred in fifth level in Basic Degree. This survey focuses two public schools and a particular school on Santa Maria-RS. This creates relations with math education and computer games in this education level. Besides it has created relations with game style, math contents and yours expectations about a different game uses new technologies. We hope to identify the importance of methods changes that attends the students needs. This survey gives enfasy to interdisplinarity for math teaching/learning proces with computer games, intensified for computer games using. This way it believes that learning could be more significant and contextualized with culture and new technologies. Keywords: Math Learning, Computer Games, and Interdisciplinarity.
\end{abstract}

*Licenciada em Matemática, cursando Mestrado em Educação (Aluna Especial) na Universidade Federal de Santa (UFSM).

**Analista de Sistemas e Mestre em Ciência da Computação. Professor nos cursos de Desenvolvimento de Jogos \& Entretenimento Digital e Engenharia da Computação na Universidade do Vale do Rio dos Sinos (UNISINOS). Sócio-diretor da empresa de entretenimento Ludens Artis.

E-mail: j rbitt@ludensartis.com.br W eb: http://www.inf.unisinos.br/ jrbitt V. $3 \mathrm{~N}^{\circ} 1$, Maio, 2005 


\section{Introdução}

O uso da Informática na Educação faz parte de um processo natural do avanço da ciência, não tendo mais sentido a discussão sobre usar ou não o computador nas escolas, pois ele está inserido, diretamente ou indiretamente, no cotidiano das pessoas e é um instrumento, quase que obrigatório, em todos os setores da sociedade. Os aprendizes, na sua maioria, utilizam o computador como entretenimento (jogos, Internet, desenhos) e, muitas vezes despendem muito tempo nos computadores do que em outras atividades.

Então, por que não se considerar as preferências do aluno? Por que não se utilizar do computador, mas precisamente dos jogos computadorizados, como instrumento mediador do processo de ensino/aprendizagem?

A Matemática é uma das disciplinas inserida no contexto dos conteúdos programáticos que se caracteriza de forma negativa, devido ao fato de não despertar o interesse e conseqüentemente não ser atrativa ao aprendiz. Essa disciplina é responsável por altos índices de reprovação dos educandos, tanto no Ensino Fundamental como no Ensino Médio, sendo responsável, muitas vezes, pela evasão escolar. Paradoxalmente, os princípios matemáticos são estudados de forma dissociada da realidade do aprendiz tornando-se pouco significativo para ele, em virtude disso, passa a considerar a matemática como algo absolutamente teórico e distante de seu cotidiano.

Urge a reflexão sobre uma aprendizagem que atenda às necessidades recorrentes dos aprendizes, com uma visão diferenciada, a qual remete-se a uma metodologia que proporcione a construção do conhecimento de uma forma desfragmentada, pois o conhecimento global propicia aos educandos tornarem-se cada vez mais críticos/reflexivos, curiosos e criativos num amplo sentido.

Situações reais ou imaginárias as quais possuam significados provocam emoções, conforme Gómez (2004), o processo de conhecimento abrange alguns componentes no cérebro, entre eles se destacam: o neocórtex que coleta as informações e é o centro do pensamento e a amígdala cerebral que é o centro do sistema límbico, sendo a principal processadora de informações emocionais, estando ligada aos processos de aprendizagem, a sua interação com o neocórtex decide a quantidade de efeito emocional que deve conter cada pensamento. Em decorrência disto, quanto mais emoção maior a chance de que a amígdala cerebral envie as informações ao armazenamento da memória a longo prazo. Em consonância com o processo do conhecimento cerebral, devem-se despertar emoções nos educandos, oportunizando situações significativas na aprendizagem. Um bom exemplo disso é o uso de jogos computadorizados, porque despertam os interesses dos aprendizes, desafiando-os a montar estratégias e propiciando os envolvimentos emocionais, reforçando assim, a relevância de utilizá-los como instrumento mediador da aprendizagem e facilitador do trabalho interdisciplinar.

Como afirma Barthes (1988, apud, MACHADO, 1994, p. 181), “O interdisciplinar de que tanto se fala não está em confrontar disciplinas já constituídas das quais, na realidade, nenhuma consente em abandonar-se", mas sim em debater, dialogar e construir uma situação contextualizada abrangendo diversas áreas do conhecimento, em inter-relação umas com as outras, de modo que a compreensão dos conteúdos envolvidos não se conceba isoladamente. Estar preparado para um trabalho interdisciplinar é deixar de lado as vaidades e dispor-se a construir, reconstruir e organizar os conhecimentos, como afirma Morin (2001, p. 24), "o conhecimento comporta, ao mesmo tempo, separação e ligação, análise e síntese", no qual de forma fragmentada não propicia ao indivíduo enfrentar os desafios da complexidade nessa era planetária, onde constantemente surgem novas informações. A interação tanto de 
disciplinas quanto de indivíduos requer uma cooperação de todos os sujeitos envolvidos no processo (alunos, professores, pais e toda a comunidade) e um pensamento holístico.

O pensamento holístico, como afirma Yus (2003, p.11), "ao longo do século XX, obteve o reconhecimento da própria ciência (por exemplo, a física quântica), apresentando uma visão da realidade mais complexa". Por conseguinte, preconiza a educação integral do indivíduo, concebendo o ser humano como um todo e interagindo com o seu meio sociocultural. Ter uma visão holística é perceber o indivíduo como um ser complexo, concordando com Morin (2000, p.39), "a educação deve promover a inteligência geral apta a referir-se ao complexo, ao contexto, de modo multidimensional e dentro da concepção global", pois os avanços tecnológicos tornaram todos os indivíduos do planeta, habitantes de uma única comunidade global.

Tendo em vista essa concepção holística e compreendendo a importância das emoções, de uma formação globalizada, integrando o cotidiano do aprendiz e as tecnologias computacionais, efetuou-se uma pesquisa inserida na realidade escolar para verificar as necessidades e interesses dos aprendizes sobre softwares para o ensino da matemática, desta forma criando um perfil dos aprendizes em relação aos jogos computadorizados e aos conteúdos matemáticos. Espera-se com este perfil evidenciar-se o fato de que os jogos educativos computadorizados precisam ser modernizados e adaptados para o século XXI. Essa pesquisa teve início em meados de outubro de 2004 e teve seu término em dezembro de 2004.

Para isso, este relato de pesquisa está organizado da seguinte forma: na seção 2 comenta-se a metodologia de ensino utilizada pelas escolas atualmente e, as suas consequiências na aprendizagem dos educandos; a seguir, na seção 3 apresentam-se alguns gêneros de jogos computadorizados; e na seção 4 apresenta-se a relação dos jogos computadorizados com a Educação; logo após, na seção 5 estão os dados coletados na pesquisa e a análise dos seus resultados; e para finalizar, as considerações finais.

\section{Instrução, Construção ou Aprendizagem Dialógica na Educação Matemática}

A organização curricular adotada pelas escolas, por muitos fatores os quais não cabe comentar neste momento, apresenta-se fragmentada e os conteúdos nem sempre têm significado para o aluno, pois são dissociados de sua realidade, contrariando a idéia citada por Morin (2000, p. 39.): "A educação deve favorecer a aptidão natural da mente em formular e resolver problemas essenciais e, de forma correlata, estimular o uso total da inteligência geral. Este uso total pede o livre exercício da curiosidade, a faculdade mais expandida e a mais viva durante a infância e a adolescência, que com freqüência a instrução extingue e que, ao contrário, se trata de estimular ou, caso esteja adormecida, de despertar". A descontextualização se evidencia em especial na área do conhecimento matemático, na qual numa visão tradicional, deve-se transmitir este conhecimento alheio à realidade circundante, dificultando para os alunos a aplicação em situações futuras. Os pensamentos instrutivistas que conforme Salvat (1998, p. 105, Substratum) "sustentam que o mundo é completamente estruturado em termos de entidades, propriedades e relações. O significado é algo que existe fora de nossa experiência".

Nessa perspectiva os conhecimentos se concebem de um modelo "especialista", formado por regras de produção, esquemas e relações de estímulos-resposta. Nesses termos, não há uma aprendizagem significativa, passando a ser apenas um simples treino de técnicas e demonstrações. A Matemática em quase todas as escolas, é trabalhada de maneira instrucional. Assim não relaciona os conteúdos com as experiências vivenciadas pelos alunos e não desperta a curiosidade ou poda o exercício dela, gerando temor e desprezo em grande parte dos educandos. 
Uma das maneiras de minimizar a rejeição dos alunos pela Matemática é fazer com que o professor propicie a eles a percepção das inter-relações dos conhecimentos matemáticos, como instrumento relevante para entender o mundo e sua realidade. Desta forma, uma aprendizagem dialógica contribui para a educação num amplo sentido, pois conforme Imbernón (2001, p.36) "Quando falamos em aprendizagem dialógica, estamos baseando-nos em um contexto de que o ser humano é muito complexo, que no aprender interagem muitos elementos e que é muito importante um elemento de conexão com o mundo social". Com uma visão holística, considera-se o indivíduo como um todo, de maneira comunicativa, cooperativa e interdisciplinar. Algumas correntes construtivistas defendem a contextualização e a construção do conhecimento de maneira significativa, mas enfatizam apenas com os conceitos individuais, preocupados com a aprendizagem do indivíduo e não considera a construção do conhecimento de forma cooperativa (todos os sujeitos construindo juntos os conhecimentos, dialogando e respeitando às diversidades). Conforme Freire (1996), devem-se respeitar os saberes que os educandos trazem consigo e discutir a razão de ser de alguns desses saberes, em relação com os conteúdos trabalhados na escola. Deste modo, relacionar esses saberes da vida cotidiana dos alunos com os conteúdos propostos facilita a compreensão e contribui para minimizar a distância entre as disciplinas.

Estas idéias reforçam o pensamento de Machado (1995), quando propõe que a escola deve buscar globalizar, expandir, flexibilizar as fronteiras de cada disciplina, buscando por meio do computador, em especial os jogos computadorizados, contribuir com este processo, oportunizando um mundo de interações e diversidades, podendo assim em apenas um jogo trabalhar diversos saberes, como a geografia, a matemática e a história, explorando mapas, utilizando escalas, transformações de unidades de medida, tipos de rochas, acontecimentos históricos no local e muitos outros temas envolvendo aventura, música, arte, propiciando a interação entre todas as disciplinas, trabalhando de maneira transdisciplinar. Paulo Freire numa entrevista com Adriano Nogueira (1994, p.19-20, apud ANDREOLA,1999, p. 69-70), relata o seguinte: "Uma das razões e pela qual necessitamos trabalhar de forma transdisciplinar é a própria busca da objetividade.

Vejamos isso aí: minha reflexão trabalha em direção à totalidade do real. E a totalidade da realidade é transdisciplinar (ou multidisciplinar). Neste sentido, eu diria que a transdisciplinaridade se impõem à subjetividade que reflete". Concordando com Freire, para entender e aprender deve-se trabalhar essa totalidade, pois o indivíduo em sua complexidade necessita ser visto como tal, tanto na educação que atualmente separa, compartimenta, isola, mecaniza os conhecimentos em vez de contextualizar e globalizar de forma cooperativa, como em todas as atividades cotidianas.

\section{Alguns Gêneros de Jogos Computadorizados}

Para apresentar os dados e os resultados da pesquisa é necessário primeiramente caracterizar o conceito de gêneros de jogos computadorizados e compreender cada gênero e estilo de jogo.

Não existe um consenso sobre uma taxonomia dos jogos computadorizados, mas a classificação dos jogos permite determinar um conjunto de características comuns que facilita o desenvolvimento dos enredos, dos motores e das interfaces gráficas. Pode-se citar os jogos de estratégia que implica em definir qual a melhor decisão a ser tomada para obter o fim esperado; simulador, que de acordo com Valente (2005), envolve a criação de modelos dinâmicos e simplificados do mundo real, permitindo experiências que seriam perigosas, como pilotar um avião, manipular substâncias químicas, etc; esporte, que envolve todos os tipos de práticas esportivas; passatempo, jogos de distração, como por exemplo, paciência e jogos de carta; aventura, jogo que compreende situações desafiadoras e emocionantes geralmente envolvendo a resolução 
de enigmas; educacional, que tem um objetivo pedagógico explícito e o RPG (RolePlaying Game), que é um jogo de representação de papéis, no qual a cooperação e a criatividade são os principais elementos. Neste jogo os personagens podem tomar decisões e mudar o curso da história, mas assumindo as consequiências de seus próprios atos, incentivando deste modo, o senso de responsabilidade. Existem o "RPG de mesa" e o digital (Bittencourt \& Giraffa, 2003a): o de mesa, é vivenciado presencialmente com uma história a ser interpretada; o digital, é mediado peloccomputador inclusive através da $w e b$.

Para facilitar a reflexão que será efetuada na próxima seção é importante destacar o conceito de estilos de jogos propostos por Rollings \& Morris (2000). Esta classificação é baseada na concepção dramática destacando os gêneros como a composição de diferentes estilos da mesma forma que é usado em obras dramáticas como o teatro, a literatura e o cinema. Estes estilos são os seguintes: ação, aventura, estratégia, simulação, quebra-cabeça, brinquedos e educacionais. Estes estilos referemse à forma que o jogo é executado e a combinação destes elementos podem originar um gênero que caracteriza os jogos. Por exemplo, para os autores, o gênero RPG é uma representação computacional dos RPGs de mesa com elementos de simulação, ação e aventura. Usando essa mecânica passa-se a considerar combinações de estilos ao invés de adotar um enfoque determinista de uma única classificação. Nesta abordagem existe uma concepção difusa onde cada jogo poderá apresentar níveis diferentes de cada um dos estilos, ou seja, um nível de estratégia e um nível de aventura, por exemplo.

\section{A Mudança de Significado dos Jogos Educativos}

Clua, Junior \& Nabais (2002) realizaram uma pesquisa com jovens de 10 a 17 anos, de classe média e moradores da cidade do Rio de Janeiro com o objetivo de verificar quais as razões que tornam os jogos computadorizados tão atrativos para os jovens e o que eles pensam sobre os jogos educacionais. Para $85 \%$ dos jovens o que torna os jogos atrativos é o desafio. Além disso, os jovens preferem ambientes imersivos com histórias ricas, jogos com qualidade gráfica e com personagens cuja Inteligência Artificial é sofisticada. Destes jovens 68\% consideram os jogos educativos ruins e ninguém considera estes jogos ótimos. Os principais problemas dos jogos educacionais listados pelos jovens são os seguintes: carecem de desafios grandes e motivadores; baixo grau de imersão; pelo fato de serem elaborados por pedagogos a ênfase principal do jogo é a educação; e em geral possuem baixa qualidade, pois são desenvolvidos com baixo orçamento.

Infelizmente a comunidade de Informática na Educação ainda possui um conceito de jogo educativo na década de 80 proposto por Coburn, Kelman, Roberts et al (1988). Lembrando que neste período o videogame usado pela sociedade era o ATARI com uma série de limitações tecnológicas de hardware e atualmente existem diferentes hardwares com grande poder de processamento.

Assim diante deste contexto devemos repensar o significado dos "jogos computadorizados educativos". Os jogos que denominamos educativos possuem um um fraco apelo entre os jovens, baixa qualidade e um enfoque altamente conteudista.

Nesses jogos existe uma proposta pedagógica explícita, seu principal objetivo é ensinar algo de uma forma lúdica. São conhecidos como eduntainment.

Como foi visto anteriormente, para Rollings \& Morris (2000), existem os estilos de jogos e estes não são categorizados em um único grupo, ou seja, em geral os jogos apresentam características de diferentes estilos. Um dos estilos propostos por Rolling \& Morris é o estilo educacional, cujo aprendizado é V. $3 \mathrm{~N}^{\mathrm{o}}$ 1, Maio, 2005 
efetuado através da prática. Baseandose nesta concepção de Rollings \& Morris que permite que os jogos assumam diferentes estilos pode-se afirmar que os jogos podem ser desenvolvidos com um estilo educativo.

Assim, por exemplo, podem existir jogos de ação, de estratégia, de RPG, de esporte educativos.

Para Bittencourt (2004), destaca-se que para compreender esta questão referente aos jogos ditos educativos é importante diferenciar a mecânica de um jogo e o seu conteúdo e que ambas possuem caráter educativo. Existem jogos que possuem um conteúdo cuja temática envolvem aspectos de extrema violência, sexo, entre outras características indesejáveis de serem abordados em um espaço de aprendizagem, tais como as salas de aula. O jogo Grand Theft Auto da RockStar Games é um exemplo de jogo cujo protagonista é um criminoso e as missões oferecidas pelo jogo envolve questões ilegais realizadas no submundo de uma cidade fictícia. Entretanto este jogo é uma mistura de ação e aventura. O jogo Grim Fandango da Eletronic Arts também possui estes mesmos estilos, entretanto sua temática é diferenciada, pois trata de uma fábula que envolve o Dia dos Mortos, um evento importante culturalmente no México.

Se considerarmos os seguintes jogos, o Sim City 2000 da Eletronic Arts e o Ages of Empires da Microsoft foram desenvolvidos sem uma intenção de educar, também poderiam ser utilizados no escopo escolar pelo fato de possuírem um conteúdo que pode ser explorado de forma educacional. O que deve ser considerado é o conteúdo de um jogo, pois a mecânica dos jogos computadorizados é implicitamente educativa.

Andrade, Zavaleta, Vaz et al (2003) consideram que os jogos computadorizados inteligentes com objetivos psicopedagógicos bem definidos podem ser usados para desenvolver habilidades cognitivas, tais como criatividade e a visão espacial.

No caso da comparação entre Grim Fandango e o Grand Thief Auto destacam-se os estilos, a mecânica do jogo que permite o desenvolvimento de habilidades metacognitivas, tais como a resolução de problemas. A diferenciação está na temática.

Portanto quando se utiliza o termo jogos computadorizados educativos referemse a um jogo que possui explicitamente uma proposta pedagógica, entretanto não se exclui o caráter educativo de todos os jogos computadorizados mesmo sem um propósito pedagógico explícito, que poderiam ser chamados de jogos didáticos.

\section{Coleta de Dados e Análise dos Resultados}

O objetivo desta investigação é verificar os gêneros de jogos computadorizados e os conteúdos de matemática que os aprendizes mais se identificam ou não e obter uma proposta dos mesmos para criação de jogos de matemática diferenciados, que possibilitem a construção do conhecimento e não apenas a reprodução de técnicas de maneira comportamentalista. É importante destacar que a proposta não enquadra-se nos objetivos desse relato sendo efetuado posteriormente.

A pesquisa foi realizada por meio de um questionário com 121 alunos numa faixa etária entre 11-13 anos, de ambos os sexos, cursando a quinta série do ensino fundamental de duas Escolas da rede Pública, identificadas por A e B e uma Escola da rede Particular, no município de Santa Maria, no interior do Rio Grande do Sul. A Escola Pública A está situada no centro da cidade, abrangendo, na sua maioria, alunos que residem nas suas proximidades e a Escola Pública B está situada na periferia, logo, grande parte dos alunos, encontra-se em situações materiais menos favorecidas. Na escola A não tem laboratório de informática, mas segundo os alunos, todos eles já jogaram algum jogo no computador. A escola B possui laboratório de informática e os alunos têm acesso a ele.

O questionário aplicado é composto por cinco perguntas, nas quais duas objetivas e três dissertativas. Nas perguntas objetivas, os alunos poderiam marcar uma 
ou duas alternativas. $\mathrm{Na}$ escola particular, 73 alunos responderam o questionário totalizando 146 opções; nas escolas públicas A e B, cada uma com 24 alunos totalizando 48 opções para cada escola. A seguir, encontram-se as perguntas e os resultados obtidos por elas:

1) Quais os gêneros de jogos computadorizados que você mais gosta?

\begin{tabular}{|l|l|l|l|}
\hline & Escola Particular & Escola pública A & Escola pública B \\
\hline Estratégia & 09 & 06 & 04 \\
\hline Simulador & 11 & 03 & 04 \\
\hline Aventura & $\mathbf{2 2}$ & $\mathbf{1 3}$ & 05 \\
\hline Passatempo & 01 & 04 & 06 \\
\hline RPG & $\mathbf{3 6}$ & 01 & 04 \\
\hline Esporte & 13 & $\mathbf{1 0}$ & $\mathbf{1 2}$ \\
\hline Educacional & 01 & 0 & 01 \\
\hline Em branco & 47 & 08 & 12 \\
\hline Nulos & 06 & 03 & 0 \\
\hline Total & $\mathbf{1 4 6}$ & $\mathbf{4 8}$ & $\mathbf{4 8}$ \\
\hline
\end{tabular}

Quadro 1 - Número de opções de preferência dos alunos

Através da análise do Quadro 1 verifica-se que na Escola Particular 24,66\% dos alunos preferem RPG e 15,07\% jogos de aventura. Na Escola A, 27,08\% gostam de jogos de aventura e 20,83\% de esporte. Na Escola B, 25\% apreciam mais os jogos de esporte e $12,5 \%$, jogos de passatempo. Constato-se que o RPG foi o gênero preferido dos alunos da escola particular. Destaca-se que na Escola B, 25\% deixaram a questão em branco. Nas escolas públicas A e B o gênero de preferência dos alunos foram respectivamente: aventura e o esporte, esses dois gêneros podem estar inseridos no RPG. Destaca-se que na escola particular o gênero de jogo preferido é o RPG, enquanto que nas escolas públicas o mesmo está entre os jogos de menor preferência, devido ao fato, na sua maioria, de não conhecerem este jogo diferenciado, criativo e desafiador, no entanto os alunos da Escola Pública A, apontaram o gênero aventura como sendo o seu preferido, isso indica a vontade de ter algo emocionante relacionado ao contexto sociocultural deles. Apesar da escola pública B possuir laboratório de informática, não são oferecidos jogos ou softwares que estimulem a criatividade dos alunos, deste modo acabam conformando-se com um simples jogo de esportes.

2)Quais os gêneros de jogos computadorizados que você menos gosta?

\begin{tabular}{|l|l|l|l|}
\hline & Escola Particular & Escola pública A & Escola pública B \\
\hline Estratégia & 13 & 06 & 05 \\
\hline Simulador & 07 & 01 & 06 \\
\hline Aventura & 0 & 01 & 01 \\
\hline Passatempo & $\mathbf{2 1}$ & $\mathbf{1 0}$ & $\mathbf{0 8}$ \\
\hline RPG & 04 & 03 & 06 \\
\hline Esporte & 06 & 04 & 01 \\
\hline Educacional & $\mathbf{2 6}$ & $\mathbf{1 0}$ & $\mathbf{0 8}$ \\
\hline Em branco & 65 & 10 & 13 \\
\hline Nulos & 04 & 03 & 0 \\
\hline Total & 146 & 48 & 48 \\
\hline
\end{tabular}

Quadro 2 - Número de opções de rejeição dos alunos 
Considerando o Quadro 2, na Escola Particular, 17,81\% dos alunos indicaram os jogos educacionais e 14,38, passatempo. E $65 \%$ deixaram a questão em branco evidenciando suas preferências pelos jogos computadorizados. Nas Escolas A e B as escolhas foram idênticas às da Escola Particular, variando apenas nos percentuais: jogos educacionais - Escolas A e B: $20,83 \%$ e 16,67\% respectivamente; jogos de passatempo - Escolas A e B: 20,83\% e 16,67\% respectivamente.

Nesta questão há um consenso entre a Escola Particular e as Escolas Públicas, os gêneros educacionais e passatempo foram desprezados pela maioria dos alunos de ambas as escolas. Por conseguinte, demonstra-se que a forma de fazer jogos educativos está equivocada conforme foi teorizado nas seções 3 e 4 .

3) Qual o conteúdo de matemática que você mais gosta?

Na Escola Pública A, 25\% dos alunos responderam radiciação e 20\%, geometria; na Escola Pública B, 33\% as frações e $25 \%$, as quatro operações e na escola particular, $38 \%$ as frações e $34 \%$, as expressões numéricas. As frações é consenso entre a Escola Pública B e a particular, as quatro operações e as frações estão inseridas em todos os conteúdos citados, logo para gostar de radiciação e geometria, necessita-se de conhecimentos nos mesmos.

\section{4) Qual o conteúdo de matemática que você menos gosta?}

$\mathrm{Na}$ Escola A, 20\% dos alunos responderam o cálculo de áreas; na Escola B, 29\% as frações e na Escola Particular, $32 \%$ as potências e $23 \%$, que eram as frações. Os demais variaram entre os outros conteúdos, tanto no item três quanto no item quatro. Em geral as respostas se contradizem, pois no caso da Escola A, gostar de geometria e não gostar de cálculo de áreas é estranho, porque elas estão diretamente relacionadas. Já na Escola B, as frações dividiram as opiniões, devido, serem apontadas também como a preferência. Da mesma forma na particular, com relação às frações.

Desse modo, evidencia-se que os conteúdos estão sendo trabalhados de maneira fragmentada, sem relações entre eles, algo que não poderia ser feito, pois todos esses conteúdos estão diretamente ou indiretamente relacionados.

Em relação à questão 5, cujos aprendizes foram questionados como que eles gostariam que fosse um jogo computadorizado de matemática, foram dadas inúmeras respostas livres que necessitam ser analisadas em uma análise de discurso mais detalhada que caracterizaria um trabalho futuro para ser efetuado. Em geral os aprendizes citaram a questão da diversão e que pudessem de fato aprender se divertindo.

Outro fato interessante de destacar-se é que os alunos da escola particular elaboraram com mais detalhes propostas de jogos computadorizados de matemática, sendo que a maioria propôs um jogo de RPG, divertido, com muitas aventuras e desafios.

Os aprendizes de um modo geral investem no prazer lúdico, no desafio do momento, na alegria, às vezes também, nos esforços sofridos a fim de vencer os obstáculos. O fato é que para eles, não se joga objetivando adquirir conhecimentos de uma disciplina escolar, mas o de se divertir. Por que não aproveitar a motivação dos alunos pelos jogos, em especial, os computadorizados, para inseri-los num contexto no qual se aprende pelo ato de jogar? Se os aprendizes estão jogando os ditos jogos educativos que a maioria não gosta e acham que esses jogos são monótonos o jogo perde seu sentido, pois jogo sem prazer não é jogo. É um recurso interessante que atende o pensamento de Macedo(2005, p. 17) quando afirma que: "Escola obrigatória que não é lúdica não segura os alunos, pois eles não sabem nem têm recursos cognitivos para, em sua perspectiva, pensar na escola como algo que lhes será bom em um futuro remoto, aplicada a profissões que eles nem sabem o que significam”. 
As respostas dadas pelos alunos para as questões referentes ao conteúdo de matemática mostra o que foi afirmado na seção 1 do presente artigo, o conteúdo matemático está desarticulado e mecanicista, tornando os alunos confusos, com dificuldades de posicionar-se. Conforme havia sido constatado por Clua, Junior \& Nabais (2002) os jogos educativos e no estilo passatempo são os jogos que mais possuem aceitação no âmbito escolar pela parte da direção e coordenação pedagógica, entretanto são os gêneros mais detestados pelos aprendizes. Logo, gera-se um desalinhamento nos objetivos e o que era para ser prazeroso passa a ser enfadonho.

Percebeu-se que em geral o RPG recebeu destaque entre os aprendizes. O RPG sendo um jogo de cooperação e de interação torna-se um grande instrumento pedagógico, facilitando o trabalho interdisciplinar. E por ser uma aventura, despertam emoções, reforçando, assim, a contribuição no processo de aprendizagem. Em razão disso, acredita-se que possa contribuir significativamente para aprendizagem matemática. Os alunos ao interpretarem os personagens receberão tarefas, desafios e a fim de vencer os obstáculos terão que tomar algumas decisões estratégicas, para o qual precisarão dos conhecimentos adquiridos nas aulas. Deste modo, motivar-se-á os alunos a estudarem os conteúdos os quais servirão de subsídios a alcançar o objetivo final (vivenciar a aventura e sobreviver a ela). Utilizar o RPG com propósitos educacionais pode tratar-se de um recurso valioso, visto que os alunos gostam deste jogo, ao contrário, conforme se verificou na pesquisa, os jogos educacionais foi desprezado pela maioria dos alunos, em razão de serem meramente informativos e sem desafios.

\section{Considerações finais}

As mudanças de metodologia se fazem necessárias, principalmente na Matemática, pois além de não flexibilizar as fronteiras das disciplinas, está se trabalhando de forma fragmentada dentro da própria disciplina de matemática, porque os alunos não conseguem estabelecer relações entre conteúdos que estão diretamente relacionados, se contradizendo nas suas opiniões. Os aprendizes estão inquietos numa perspectiva de emoção, aventuras e diversão. Como não encontram isso em sala de aula, não são motivados a aprender. Destacar o lúdico como uma maneira de contribuir para motivar os aprendizes a buscar, pesquisar, construírem o conhecimento junto de forma cooperativa, seria uma forma de ter o aprendiz na escola, não por obrigação, mas por um sincero desejo de aprender.

A dicotomia das Escolas Públicas e a Escola Particular são visíveis, pois se observou que os alunos, da classe menos favorecida financeiramente, tiveram dificuldades para transmitir uma opinião clara sobre a questão em que eles deveriam expressar as suas expectativas de jogos computadorizados de matemática, diferentemente dos alunos de classe média alta que, na sua maioria, foram muito criativos. Deste modo, o contexto sócio-econômico e sócio-cultural podem influenciar na opinião dos alunos.

Também conclui-se que necessita-se efetuar uma reforma na concepção dos ditos jogos educativos que na verdade são jogos didatizantes. A forma que estes estão sendo concebidos caracterizam-se como atividades desinteressantes pelos aprendizes e não auxiliam esses a estabelecerem relações entre a matemática e as situações cotidianas. A aversão pelos jogos educativos/passatempo e o forte interesse por jogos divertidos e imersivos caracterizou esta pesquisa da mesma forma que caracterizou a pesquisa de Clua, Junior \& Nabais (2002).

Quanto aos trabalhos futuros, espera-se efetuar uma análise de discurso das questões dissertativas e aprofundar os estudos estatísticos dos dados coletados visando estabelecer correlações entre atributos que caracterizam os aprendizes em relação aos jogos computadorizados e ao estudo da matemática. Tendo concluído estes estudos será V. $3 \mathrm{~N}^{\circ}$ 1, Maio, 2005 
possível especificar características de softwares educativos que poderão ser usados na matemática. Por último, destaca-se que maiores informações sobre o uso dos jogos computadorizados no processo de ensino-aprendizagem, mais especificamente, RPG Digitais podem ser obtidas em http://www.inf.pucrs.br/ jricardo/revolution.

\section{Referências Bibliográficas}

ANDRADE, Leila; ZAVALETA, Jorge; VAZ, Francine; et al. Jogos Inteligentes são Educacionais? In: XIV Simpósio Brasileiro de Informática na Educação. Rio de Janeiro: SBC, 2003, pp. 699-707.

BITTENCOURT, João R.; GIRAFFA, Lucia M.M. A Utilização dos RolePlaying Games Digitais no Processo de Ensino-Aprendizagem. Relatório Técnico $\mathrm{n}^{\circ}$ 031, Porto Alegre: PPGCC/FACIN/PUCRS, 2003a, 62 p.

BITTENCOURT, João R.; GIRAFFA, Lucia M. Modelando Ambientes de Aprendizagem Virtuais utilizando Role-Playing Games In: XIV Simpósio Brasileiro de Informática na Educação. Rio de Janeiro: SBC, 2003b. p. 718-727.

BITTENCOURT, João R. Um Framework para Criação de Jogos Computadorizados Multiplataforma. Porto Alegre: PUCRS/PPGCC, 2004, 199 p.

COBURN, Peter; KELMAN, Peter;ROBERTS, Nancy et al. Informática na Educação.Rio de Janeiro:LTC, 1988, 298 p.

CLUA, Esteban Walter Gonzalez; JUNIOR, Carlo Luciano de Luca; NABAIS, Rodrigo José de Moraes. Importância e Impacto dos Jogos Educativos na Sociedade. In: I Workshop Brasileiro de Jogos e Entretenimento Digital. SBC: Fortaleza, 2002.

FREIRE, Paulo. Pedagogia da Autonomia: saberes necessários à prática educativa. Paz e terra, São Paulo. 1996

ONTORIA PENÃ, A; LUQUE, A; GÓMES, J.P.; tradução: Silvia Mariângela Spada. Aprender com Mapas Mentais. Madras, São Paulo. 2004.

IMBERNÓN, Francisco. A educação do futuro não está tanto nos professores, mas no apoio da comunidade. Pátio, revista pedagógica, n. 16, p. 34-38, 2001.

MACEDO, L; PETTY, A.L. S; PASSOS, N. C. Os Jogos e o Lúdico na aprendizagem escolar. Artmed, Porto Alegre. 2005.

MORIN, Edgar; tradução: La tête bien faite. A Cabeça Bem-feita: repensar a reforma, reformar o pensamento. 3.ed. Bertrand Brasil, Rio de Janeiro. 2001.

MORIN, Edgar; tradução: Catarina Eleonora F. da Silva e Jeanne Sawaya. Sete Saberes necessários à Educação do Futuro. 2. ed. Cortez, São Paulo. 2000.

MACHADO, Nílson José. Epistemologia e didática: As concepções de conhecimento e inteligência e a prática docente. Cortez, São Paulo. 1994.

ROLlingS, Andrew. MORRIS, Dave. Game Architecture and Design. Arizona: Coriolis, 2000, 742 p.

SALVAT, Begoña Gros; Direção Ana Teberosky e Liliana Tolchinsky; tradução: Francisco Franke Settineri. Substratum: Temas Fundamentais em Psicologia e Educação. v. 2, n. 5. Artmed, Porto Alegre. 1998.

YUS, Rafael. As comunidades de aprendizagem na perspectiva holística. Pátio, revista pedagógica, n. 24, p. 10-13, 2003.

VALENTE, José Armando. Diferentes uso do computador na educação In: Em Aberto,ano 12, n.57, 1993, p.3-15. 